\title{
Dengue Fever-Triggered Malignant Hyperthermia
}

Kanakka Hewage Dammika Madhusankha ${ }^{1}$, Harshani Fernando ${ }^{2}$, Sanupa Kumarasiri ${ }^{2}$, Ganesha G. Liyanarachchi ${ }^{2}$

1. Emergency Medicine, National Hospital, Kandy, LKA 2. Internal Medicine, National Hospital of Sri Lanka, Colombo, LKA

Corresponding author: Kanakka Hewage Dammika Madhusankha, dammika.edu@gmail.com

\begin{abstract}
Malignant hyperthermia (MH) is a genetic skeletal muscle disorder characterized by hypermetabolic crisis usually triggered by anesthetic drugs. Non-anesthesia-triggered or awake $\mathrm{MH}$ is rare or under-reported. Other than anesthetic drugs, identified common triggers are exercise, fever, and viral infection. The literature does not report any awake $\mathrm{MH}$ cases triggered by dengue fever. We report a possible case of dengue fever-triggered awake MH. The main aim of reporting this case is to raise awareness of possible malignant hyperthermia in dengue patients and of a clinical grading system (CGS) for early diagnosis, as early treatment with dantrolene sodium reduces the mortality rate.
\end{abstract}

Categories: Anesthesiology, Emergency Medicine, Internal Medicine

Keywords: metabolic crisis, dengue fever, rhabdomyolysis, hyperthermia crisis, non-anaesthetic malignant hyperthermia, dantrolene

\section{Introduction}

Malignant hyperthermia is a rare genetic disorder denoted by hypermetabolism in skeletal muscle and is usually triggered after susceptible individuals are given volatile anesthetics or depolarizing muscle relaxants [1].

Life-threatening non-anesthetic-triggered malignant hyperthermia (MH) episodes have been identified as "awake" MH. The characteristic clinical findings are the sudden onset of unexplained tachycardia, hyperthermia, tachypnea, skeletal muscle spasms, severe mixed acidosis, and hyperkalemia [2-4].

Awake or non-anesthetic MH episodes are seen in physically fit individuals who have been exposed to excessive heat, vigorous exercise, febrile and flu-like illnesses like influenza A. Of all the triggers, influenza A causes a highly aggressive onset with a rapid increase in body temperature, rhabdomyolysis, and disseminated intravascular coagulation $[1-2,4]$.

Review began 05/05/2021 Review ended 05/11/2021 Published 05/19/2021

๑ Copyright 2021 Madhusankha et al. This is an open access article distributed under the terms of the Creative Commons Attribution License CC-BY 4.0., which permits unrestricted use, distribution, and reproduction in any medium, provided the original author and source are credited.
A clinical grading system (CGS) can be used to assess the likelihood of MH based on a scoring system. According to this system, a patient with a score of $>50$ points has malignant hyperthermia $[5,6]$. The scoring system helps to identify acute crises in patients who have not been previously recognized as malignant hyperthermia-susceptible individuals or in situations where genetic or in vitro contracture testing is not possible.

\section{Case Presentation}

A 29-year-old, previously healthy male walked into the outpatient department (OPD) of the National Hospital of Sri Lanka with dengue non-structural protein 1 (NS1) antigen-positive fever of three days duration. Other than the three-day history of fever, he had no other significant past medical history except a failed military fitness test because of body temperature $40^{\circ} \mathrm{C}$ and muscle cramp after running $1 \mathrm{~km}$ four years previously. He denied a recent history of strenuous exercise or the use of illicit drugs. Urine or serum drug screen was not performed due to lack of facility.

On admission to the medical ward, he was conscious and rational. His temperature was $37.3^{\circ} \mathrm{C}$, his heart rate was $80 \mathrm{bpm}$, and his blood pressure was 110/60 mmHg. Hematologic analysis revealed full blood count with WBC 4,850 per microliter $\left(4.850 \times 10^{9} / \mathrm{L}\right)$, hematocrit $39 \%$, and platelets 180,000 per microliter $\left(180 \times 10^{9} / \mathrm{L}\right)$. One hour after being admitted to the medical ward, he developed a high fever with a temperature of $40.2^{\circ} \mathrm{C}$ which was treated with active cooling with IV cooled normal saline and ice water sponging. Other clinical features detected were diaphoresis, tachycardia with a heart rate of 140 beats/min, tachypnea with a respiratory rate of 40 breaths/min, skeletal muscle spasms, and limb rigidity. Arterial blood gas (ABG) revealed the following: pH - 6.9, PCO2 - $101 \mathrm{mmHg}, \mathrm{HCO} 3$ - 8 (mmol/L), BE - (-14), PO2 - $105 \mathrm{mmHg}$, SpO2 $95 \%$, and $\mathrm{K}+-6.8$. Hyperkalemia was managed by giving intravenous 10 units of soluble insulin and $50 \%$ Dextrose infusion, Intravenous $8.4 \%$ bicarbonate $50 \mathrm{ml}$ infusion. Intravenous $10 \%$ calcium gluconate $10 \mathrm{ml}$ was given to protect cardiomyocytes. 


\section{Cureus}

The patient's clinical condition deteriorated after 10 minutes, and he developed increasing muscle tone with trismus, opisthotonic posture, hyperthermia, severe metabolic and respiratory acidosis despite hyperventilation, refractory hyperkalemia ( $8.8 \mathrm{meq} / \mathrm{l})$, and hypocalcemia. ABG results were as follows: $\mathrm{PH}$ 7.03, $\mathrm{PCO} 2-100 \mathrm{mmHg}, \mathrm{HCO} 3$ - low, and lactate - 10. Urine was brown in color and urine for myoglobinuria report received as positive after 4 hours.

Then the patient was emergently intubated after giving IV atracurium $60 \mathrm{mg}$ (A non-depolarizing muscle relaxant). He progressed to asystolic cardiac arrest, which was treated according to the advanced life support (ALS) protocol. The patient's hyperkalemia was refractory to insulin and dextrose infusion and bicarbonate infusion. Salbutamol was not started due to tachycardia. He expired after two hours of attempted resuscitation.

\section{Discussion}

\section{Literature review}

A study conducted on 286 anesthesia-triggered MH cases was used to develop a clinical grading system (CGS) to assess the likelihood of MH. The CGS (Table 1) assesses the likelihood of MH without the use of specialized diagnostic testing such as muscle biopsy. It is based on points given for abnormal signs and laboratory findings observed during an acute hypermetabolic crisis [7].

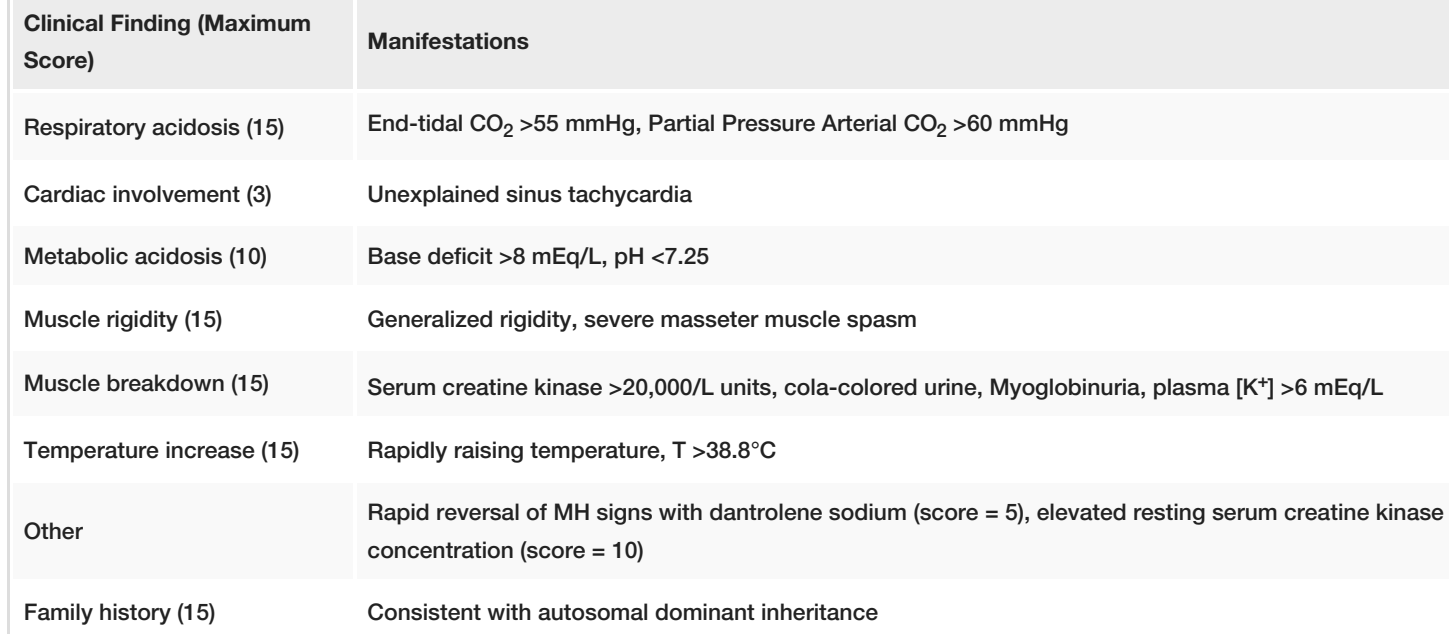

TABLE 1: Clinical grading scale for malignant hyperthermia

Another study conducted on 136 non-anesthesia-triggered MH cases found that $75 \%$ of patients presenting with post-viral chronic fatigue had a positive caffeine halothane contracture test (CHCT). The author suggests that patients with post-viral chronic fatigue may test positive to the CHCT. This finding requires further study of disordered calcium homeostasis in the skeletal muscle following post-viral fatigability $[8,9]$.

In other reported cases and case series of awake $\mathrm{MH}$, the triggers were sports activity, exercise, fever, and influenza A [3]. MH triggered by dengue fever has not been reported.

Our patient with dengue fever walked to the hospital with stable vital parameters but, shortly after arrival, started showing early features of MH. The main clinical features were unexpected elevation of PCO2 despite increased minute ventilation, skeletal muscle rigidity, high body temperature, tachycardia, severe mixed acidosis, and hyperkalemia. The patient responded poorly to general medical management. He scored 71 points on the MH clinical scoring system, while the cut-off for MH is 50 points (Table 2). Clinically malignant hyperthermia was almost certain [8-9]. As there was no other apparent triggering factor for $\mathrm{MH}$, our patient was diagnosed as a case of awake or non-anesthetic $\mathrm{MH}$ triggered by dengue fever. 


\section{Cureus}

\section{Expected Clinical Feature}

Process I - Muscle rigidity

Process II - Myonecrosis

Process III - Respiratory Acidosis

Process IV - Temperature increase

Process V - Cardiac Involvement

Others (1)

Other (2)

Total score
Patient's Clinical Finding

Score

Generalized rigidity

Serum creatine kinase and urine myoglobin not available; $\mathrm{K}^{+}>6$

$\mathrm{PaCO}_{2}>60 \mathrm{mmgh}$

Rapid increase

Inappropriate tachycardia

Base excess more negative than $8 \mathrm{meq} / \mathrm{L}$

10

Arterial $\mathrm{pH}<7.25$

TABLE 2: Calculation of patient's likelihood of having malignant hyperthermia

The in vitro muscle contracture test (IVCT) and the caffeine halothane contracture test (CHCT) are considered to be the standard tests to identify susceptibility to MH [9]. The clinical grading system is helpful for making a clinical diagnosis in an acute situation where susceptibility to MH has not been evaluated. High clinical suspiciousness using the clinical grading system may help the clinician to start dantrolene sodium early, which reduces the mortality rate if started within 30 minutes.

\section{Conclusions}

Dengue fever can trigger malignant hyperthermia in $\mathrm{MH}$-susceptible patients. Post-trigger clinical findings are similar in anesthetic and non-anesthetic MH. Recognizing hypermetabolic crisis at the early stage is challenging; the key clinical features are unexplained tachycardia, hyperthermia, muscle rigidity, mixed acidosis, and rhabdomyolysis. The use of a clinical grading scale (CGS) may help early diagnosis, allowing the early initiation of effective treatment. Dantrolene sodium, a post-synaptic muscle relaxant that reduces contractility and energy expenditure, is an effective treatment.

\section{Additional Information}

\section{Disclosures}

Human subjects: Consent was obtained or waived by all participants in this study. Conflicts of interest: In compliance with the ICMJE uniform disclosure form, all authors declare the following: Payment/services info: All authors have declared that no financial support was received from any organization for the submitted work. Financial relationships: All authors have declared that they have no financial relationships at present or within the previous three years with any organizations that might have an interest in the submitted work. Other relationships: All authors have declared that there are no other relationships or activities that could appear to have influenced the submitted work.

\section{References}

1. Molenaar JP, Voermans NC, van Hoeve BJ, et al.: Fever-induced recurrent rhabdomyolysis due to a novel mutation in the ryanodine receptor type 1 gene. Intern Med J. 2014, 44:819-820. 10.1111/imj.12498

2. Lopez JR, Kaura V, Diggle CP, Hopkins PM, Allen PD: Malignant hyperthermia, environmental heat stress, and intracellular calcium dysregulation in a mouse model expressing the p.G2435R variant of RYR1. Br J Anaesth. 2018, 121:953-961. 10.1016/j.bja.2018.07.008

3. Zvaritch E, Gillies R, Kraeva N, Richer M, Jungbluth H, Riazi S: Fatal awake malignant hyperthermia episodes in a family with malignant hyperthermia susceptibility: a case series. Can J Anaesth. 2019, 66:540-545. 10.1007/s12630-019-01320-z

4. Rosenberg H, Pollock N, Schiemann A, Bulger T, Stowell K: Malignant hyperthermia: a review. Orphanet J Rare Dis. 2015, 10:93. 10.1186/s13023-015-0310-1

5. Iqbal A, Badoo S, Naqeeb R: A case report of suspected malignant hyperthermia where patient survived the episode. Saudi J Anaesth. 2017, 11:232-235. 10.4103\%2F1658-354X.203057

6. Larach MG, Localio AR, Allen GC, et al.: A clinical grading scale to predict malignant hyperthermia susceptibility. Anesthesiology. 1994, 80:771-779. 10.1097/00000542-199404000-00008

7. Larach MG, Gronert GA, Allen GC, Brandom BW, Lehman EB: Clinical presentation, treatment, and complications of malignant hyperthermia in North America from 1987 to 2006. Anesth Analg. 2010, 110:498-507. 10.1213/ANE.0b013e3181c6b9b2

8. Timmins MA, Rosenberg H, Larach MG, Sterling C, Kraeva N, Riazi S: Malignant hyperthermia testing in probands without adverse anesthetic reaction. Anesthesiology. 2015, 123:548-556.

10.1097/ALN.0000000000000732 


\section{Cureus}

9. Urwyler A, Deufel T, McCarthy T, West S: Guidelines for molecular genetic detection of susceptibility to malignant hyperthermia. Br J Anaesth. 2001, 86:283-287. 10.1093/bja/86.2.283 